\title{
Repercussões emocionais em mães de crianças com microcefalia em decorrência do Zika Vírus
}

\author{
Emotional repercussions in mothers of children with microcephaly due to Zika Virus \\ Repercusiones emocionales en madres de niños con microcefalia por virus Zika
}

Recebido: 25/04/2021 | Revisado: 05/05/2021 | Aceito: 10/05/2021 | Publicado: 27/05/2021

Franciskely Ribeiro Martins

https://orcid.org/0000-0002-7586-612X

Universidade Federal de Mato Grosso, Brasil

E-mail: franciskely94@gmail.com

Suzicléia Elizabete de Jesus Franco

https://orcid.org/0000-0002-2288-9117

Universidade Federal de Mato Grosso, Brasil

E-mail: suzicleia@hotmail.com

Arielle Carlos Costa dos Santos

https://orcid.org/0000-0001-8834-6062

Distrito Sanitário Especial Indígena - DSEI Xavante, Brasil

Alisséia Lemes Guimarães

https://orcid.org/0000-0001-6155-6473

Universidade Federal de Mato Grosso, Brasil E-mail: alisseia@hotmail.com

Pâmela Roberta de Oliveira

https://orcid.org/0000-0003-0497-6548

Universidade Federal de Mato Grosso, Brasil

E-mail: pam.roberta84@gmail.com

\begin{abstract}
Resumo
Objetivo: este trabalho tem como objetivo relatar e analisar as experiências de mães, a partir do diagnóstico de microcefalia, do filho, em decorrência da infecção pelo Zika Vírus. Materiais e métodos: esta pesquisa trata-se de um estudo descritivo, com abordagem qualitativa, realizado com duas mães de crianças com microcefalia, residentes em um município localizado na região Centro-Oeste, em Mato Grosso, no Brasil. As entrevistas foram realizadas em 2018 e analisadas por meio de análise de conteúdo, na modalidade temática. Resultados: as mães, que vivenciaram a experiência de ter um filho com microcefalia, reagiram ao diagnóstico com surpresa e desespero e ao luto com angústia e dor. Além disso, as progenitoras apresentaram pouco conhecimento sobre a doença e o prognóstico. Esta investigação evidenciou a mudança na dinâmica familiar frente à doença, e as dificuldades na interação da família com o setor básico de saúde. Conclusão: os registros apontam que é urgente a necessidade de acolhimento permanente e integral às mães, de forma que se estenda o cuidado com a saúde, não somente das crianças, mas, também, da unidade familiar.
\end{abstract}

Palavras-chave: Infecção por Zika vírus; Mães; Microcefalia; Relações familiares; Saúde mental.

\section{Abstract}

Objective: this study aims to report and analyze how mothers experience, from the diagnosis of microcephaly, of the child, as a result of Zika Virus infection. Materials and methods: this research is a descriptive study, with a qualitative approach, carried out with two mothers of children with microcephaly, living in a municipality located in the Midwest region, in Mato Grosso, in Brazil. The accounts were carried out in 2018 and analyzed through content analysis, in the thematic modality. Results: as mothers, who experience the experience of having a child with microcephaly, they reacted to the diagnosis with surprise and despair and to grief with anguish and pain. In addition, as parents of little knowledge about the disease and prognosis. This investigation evidences the change in the family dynamics, facing the disease, and the difficulties in the interaction of the family with the basic health sector. Conclusion: the records indicate that there is an urgent need for permanent and comprehensive care for mothers, so that health care is extended, not only to children, but also to the family unit.

Keywords: Zika virus infection; Mothers; Microcephaly; Family relationships; Mental health.

\section{Resumen}

Objetivo: este estudio tiene como objetivo informar y analizar cómo las madres viven, a partir del diagnóstico de microcefalia, del niño, como consecuencia de la infección por el virus del Zika. Materiales y métodos: esta investigación es un estudio descriptivo, con enfoque cualitativo, realizado con dos madres de niños con microcefalia, 
residentes en un municipio ubicado en la región Medio Oeste, en Mato Grosso, Brasil. Las cuentas se realizaron en 2018 y se analizaron mediante análisis de contenido, en la modalidad temática. Resultados: como madres, que viven la experiencia de tener un hijo con microcefalia, reaccionaron al diagnóstico con sorpresa y desesperación y al duelo con angustia y dolor. Además, como padres de poco conocimiento sobre la enfermedad y pronóstico. Esta investigación muestra el cambio en la dinámica familiar frente a la enfermedad y las dificultades en la interacción de la familia con el sector básico de salud. Conclusión: los registros indican que existe una necesidad urgente de atención permanente e integral a las madres, para que la atención de salud se extienda, no solo a los niños, sino también a la unidad familiar.

Palabras clave: Infección por el virus del Zika; Madres microcefalia; Relaciones familiares; Salud mental.

\section{Introdução}

O presente estudo destaca a importância permanente de um cuidado multiprofissional e intersetorial, com pactuações efetivas e consistentes nos diferentes níveis de atenção à saúde, a fim de proporcionar às mães e aos familiares de crianças com microcefalia, para além da assistência, um cuidado integral, de qualidade, resolutivo, humanizado e holístico. O cuidado dispensado à criança com microcefalia pode alterar a rotina familiar, comprometer a saúde emocional de todos os membros e prejudicar a própria qualidade do cuidado e as potencialidades da criança.

O vírus do Zika foi percebido pela primeira vez em macacos, no ano de 1947 em Uganda. Existem evidências que em 1950, surgiram os primeiros casos de microcefalia em seres humanos. Porém, relatos de grandes surtos vieram à tona em 2007 na Micronésia e, em 2013, na Polinésia Francesa. Em 2014, foi notificada uma doença exantemática acompanhada de outros sintomas no Brasil (Lesser \& Kitron, 2016, Pimenta, Pereira, Clode, Graça, \& 2016, Fantinato et al., 2016). No fim do ano de 2015, a microcefalia já havia se espalhado por todo o Brasil e por vários países da América. No Brasil, notou-se um aumento de casos de microcefalia na região Nordeste do país e indícios apontavam que as mães tinham apresentado erupções cutâneas e sintomatologia condizentes com a infecção do Zika Vírus durante a gestação. Por conseguinte, o Ministério da Saúde (MS) e a Organização Mundial da Saúde (OMS) decretaram uma emergência de Saúde Pública de Importância Nacional (ESPIN) relacionada ao padrão atípico de ocorrência de microcefalia no Brasil (Lesser \& Kitron, 2016, Pimenta et al., 2016), que passou a ser vista como uma ameaça de saúde pública a mulheres grávidas e seus filhos. Segundo o MS, entre as semanas epidemiológicas (SEs) 45/2015 e 40/2019 (08/11/2015 a 05/10/2019) foram confirmados 3.474 casos de pessoas contaminadas pelo Zika Vírus, e dentre esses, 78,3\% (a grande maioria) foram de recém-nascidos com microcefalia. A região Centro-oeste ocupou o terceiro lugar relacionado ao número de casos de microcefalia notificados, o que representou 7,7\% do total de notificações, com 282 casos confirmados e 41 casos de óbitos fetais, neonatais e infantis, possivelmente relacionados à infecção pelo vírus Zika (Brasil, 2019).

Diante desta situação epidemiológica, é fundamental a articulação de ações intersetoriais e multiprofissionais para a efetivação da atenção integral e humanizada às crianças com microcefalia e suas famílias, tanto no aspecto da proteção social, quanto no âmbito da saúde, visto que, a criança com microcefalia possui necessidades singulares, principalmente, relacionadas à saúde e a proteção (Costa, Bonfim, Magalhães, \& Viana, 2018).

Quando nasce uma criança, com qualquer patologia, gera nos pais diversas dúvidas, pois estão diante do desconhecido, o que pode comprometer a formação do vínculo afetivo, a aceitação do filho e a compreensão das informações sobre o prognóstico e tratamento. A gestação é um período em que os pais idealizam planos para o bebê, planos para uma criança saudável, que irá correr, brincar, conversar e ter um discernimento sem maiores dificuldades. Situações como a descoberta de uma doença frustram os planos, sonhos e as expectativas que foram criadas em relação à criança esperada, isso exige da família uma reestruturação para enfrentar tal condição (Sá \& Rabinovich, 2006, Felix, Farias, 2017, Barros, Monteiro, Neves \& Maciel, 2017).

Os pais, ao se depararem com as limitações do filho, apresentam instabilidade emocional e sentimentos como medo e incerteza afloram. Entre as dificuldades enfrentadas pela família de criança com microcefalia, destacam-se: a aceitação, o 
preconceito, o sentimento de insegurança e as inúmeras ocasiões imprevisíveis que terão de ser enfrentadas após o nascimento e prognóstico (Buscaglia, 2010, Melo, Silva, Moura, \& Barbosa, 2017).

Estudos qualitativos, publicados nos últimos anos, têm revelado que ainda há fragilidades relacionadas ao apoio e ao acolhimento das crianças com microcefalia e suas respectivas famílias, já que elas têm enfrentado inúmeras adversidades, inseguranças psicossociais e momentos de desinformação, sensação de abandono e sentimentos angustiantes (Costa et al., 2018, Oliveira \& Sá, 2017, Oliveira, Moreira, Lima, \& Melo, 2018, Oliveira et al., 2019). Este fato revela uma emergente necessidade de fortalecer a rede social destas famílias para que tenham melhores condições de vida (Sá, Galindo, Dantas, \& Moura, 2020).

Nesse contexto, é notória a importância da atuação de profissionais de várias áreas do conhecimento, com atuação interdisciplinar (Melo et al., 2017, Santos, Mercês, Souza, \& Santana, 2018), qualificados e preparados para acolher e oferecer um cuidado integral, resolutivo e holístico às crianças com microcefalia e suas famílias (Sá et al., 2020).

O período de emergência, em saúde pública, relacionado a ocorrência de microcefalia, no Brasil, já passou, contudo, milhares de crianças com microcefalia e suas respectivas famílias necessitam, permanentemente, de atenção integral à saúde, cuidado humanizado, acolhimento, orientação e, sobretudo, melhores condições de vida. Dar voz às mães, das crianças com microcefalia, deixá-las falar sobre o seu viver e sobre as mudanças experienciadas é fundamental para o fortalecimento das redes de apoio e de assistência à criança com microcefalia.

Diante do exposto, as perguntas norteadoras desta pesquisa foram: Quais os sentimentos que emergiram nas mães diante do diagnóstico da criança com microcefalia em decorrência da infecção pelo Zika Vírus? Quais mudanças ocorreram na vida familiar das mulheres a partir do diagnóstico de microcefalia dos filhos? Qual a percepção das mães sobre o acolhimento e assistência recebidos, inicialmente, nas redes de atenção à saúde? Assim, o objetivo deste estudo é relatar e analisar a experiência de mães, a partir do diagnóstico de microcefalia, dos filhos, em razão da infecção pelo Zika Vírus.

\section{Metodologia}

Trata-se de um estudo descritivo, com abordagem qualitativa, realizado com mães residentes em um município localizado na região Centro-Oeste, no estado de Mato Grosso, no Brasil.

Participaram desta pesquisa duas mães (maiores de 18 anos) de crianças com microcefalia, cujos os filhos foram diagnosticados durante a epidemia do Zika Vírus, entre os anos de 2015 e 2017. Estes foram os critérios estabelecidos para selecionar os participantes da pesquisa, dessa forma, a amostra foi composta apenas por duas mães e não houve exclusão de participantes.

As mães foram indicadas pela Secretaria Municipal de Saúde (SMS), que, após autorização, forneceu o contato telefônico das mulheres que apresentavam registros de terem tido filhos com microcefalia. Posteriormente, uma visita foi agendada para esclarecimentos sobre a pesquisa e a entrevista. Segundo informações coletadas na SMS, responsável pelo município, não houve registros de novos casos de criança com microcefalia até junho de 2020.

A coleta de dados ocorreu em janeiro de 2018, por meio de uma entrevista semiestruturada, que foi realizada no domicílio das mães, com agendamento prévio entre elas e a pesquisadora principal. Após esclarecimento sobre a pesquisa (objetivos, aspectos éticos e orientações quanto às dúvidas das mães) iniciou-se a entrevista, que foi gravada em mídia eletrônica (gravador de voz) com a aprovação das mães (as entrevistas ocorreram em momentos distintos para cada participante). A visita para realização da entrevista teve duração média de 45 minutos.

Os dados obtidos na entrevista foram tratados de acordo com a técnica de análise de conteúdo, na modalidade temática (Minayo, 2012). Após a transcrição das entrevistas na íntegra, iniciou-se a fase de pré-análise, em que as entrevistas foram submetidas a várias leituras. No segundo momento, foi realizada a análise do material para obtenção do eixo central da 
concepção do texto, ou seja, encontrar as categorias que são expressões ou palavras significativas com relevância em função das quais o conteúdo de uma fala pode ser organizado. Assim, estabeleceu-se quatro categorias: reação e sentimento diante do diagnóstico; reação e sentimento diante do óbito; dinâmica familiar; apoio da rede de atenção básica. A partir das categorias, , realizou-se interpretações, inferências e interações com o quadro teórico desenhado, inicialmente, sobre a vivência com a criança portadora de microcefalia.

Foram respeitados todos os aspectos éticos relativos à pesquisa com seres humanos, com aprovação do Comitê de Ética em Pesquisa (CEP) do Araguaia, com CAAE: 81036517.6.0000.5587 e parecer $\mathrm{n}^{\circ}$ 2.480.806. Todas as participantes assinaram o Termo de Consentimento Livre e Esclarecido. Para preservar o anonimato, a identificação das participantes foi codificada pelas letras M (Mãe), seguidas pelo número da ordem das entrevistas (1 e 2).

\section{Resultados}

A faixa etária das mães, na época da pesquisa, era entre 20 e 38 anos. A mãe um (M1) tinha 38 anos, se autodeclarou solteira, espírita e com rendimento mensal familiar de até três salários mínimos. Já a mãe dois (2) disse que tinha 20 anos, era casada, sem religião e com renda inferior a um salário mínimo. Os resultados apontaram as reações e sentimentos das mães diante dos diagnósticos e do óbito.

\subsection{Reação e sentimento diante do diagnóstico}

Descobrir que o filho nascerá com microcefalia e, consequentemente, poderá apresentar severas alterações no seu desenvolvimento pode trazer sentimentos não esperados a toda família, em específico a mãe que gesta o bebê com a esperança de ter uma gestação tranquila e um nascimento sem complicações, permeado por sentimentos de alegria e prosperidade.

Os dados revelaram sentimentos negativos entre as mães no momento em que foram informadas do diagnóstico de microcefalia dos filhos. As progenitoras reagiram com surpresa, desespero, choro e pesar com a notícia recebida:

\section{[...] Ave maria, eu chorei demais! [...] eu fiquei desesperada, nunca pensei que ia acontecer comigo. (M1)}

[...] Péssima! horrível! Não tem sensação pior! (M2)

As mães participantes deste estudo relataram que, antes do diagnóstico, tinham um escasso conhecimento sobre a microcefalia relacionada ao Zika Vírus, sendo que, o pouco que sabiam, foi adquirido por informações advindas dos meios de telecomunicação (TV, Rádio) e da internet:

[...] Até então eu não sabia o que era microcefalia, eu estava ouvindo falar só na televisão, nunca pensei que ia acontecer comigo, aí que eu fui procurar saber o que que era a microcefalia. (M1)

[...] Quando eu estava grávida, eu via bastante na televisão, mas sabia pouca coisa. (M2)

\subsection{Reação e sentimento diante do óbito}

Um dos bebês nascidos com microcefalia veio a óbito após o nascimento. O fato de terem recebido o diagnóstico e orientações, ainda na gestação, preveniu as mães para o que poderia acontecer após o parto. O relato de uma das genitoras demonstrou que ela já estava preparada caso ocorresse o óbito, e, por isso, se manteve tranquila e conformista quando isso aconteceu:

[...] Eu estava preparada, fiquei tranquila quando ela desencarnou. As meninas dentro do quarto ficaram até assim: 'Nossa nem parece que você perdeu uma filha?' O que eu vou fazer? Não posso desesperar, foi a vontade de Deus. 
(M1)

Para a M1, o enfrentamento do luto esteve diretamente ligado aos aspectos religiosos, o que pode estar relacionado ao desejo de encontrar o conforto necessário para superar os sofrimentos advindos do óbito do filho, ou na busca de respostas para compreender os motivos por estar passando pelo processo de angústia e dor. Contudo, apesar de M1 relatar conformismo em relação ao óbito, após a alta hospitalar, ela declarou ter vivido um período de sofrimento emocional com pensamentos suicidas:

[...] teve a ligação da enfermeira para me fazer essas perguntas, ela perguntou como eu estava me sentindo. E eu falei que já pensei em fazer besteira duas vezes. Ela me falou: 'Por que você não procura uma enfermeira? Vai no postinho', ela me aconselhou bem, passei pelo médico, ele me deu encaminhamento para procurar um psicólogo, passou até um calmante para mim, porque eu não estava dormindo, nem comendo. (M1)

Além dos aspectos religiosos, do sofrimento emocional, do constrangimento de compartilhar o quarto com outras mães e de ser cobrada por elas a expressar tristeza e dor diante do óbito, esta mãe ainda relatou a dor do abandono e o caminhar na solidão. A M1 expressou a ausência de apoio e participação do pai da criança, desde a gestação até a notícia do óbito.

[...] Eu fui no centro espírita, chorei tudo que eu tinha que chorar, e foi lá que eu recebi as informações mais detalhadas dela. Ele não participou de nada, eu engravidei e ele simplesmente se afastou, sofri demais depois da perda (da filha), eu queria só um abraço dele. (M1)

\subsection{Dinâmica familiar}

Quanto à dinâmica familiar, as participantes deste estudo declararam que contaram com o apoio de seus familiares, especialmente de suas mães. Além disso, a mãe, cujo filho veio a óbito (M1), revelou que passar por esta experiência, contribuiu para melhorar, significativamente, sua convivência com seus familiares. Por outro lado, a dinâmica familiar da mãe, que o filho sobreviveu e depende de seus cuidados (M2), foi completamente alterada. A M2 precisou se dedicar exclusivamente para o cuidado com os dois filhos, em especial a criança com microcefalia. A mulher não contava com a ajuda do esposo, na rotina de cuidado com as crianças, uma vez que, ele trabalhava em período integral:

[...] aprendi a valorizar mais a minha família, porque se não fosse minha família, não sei o que era de mim, principalmente minha mãe, minha mãe estava do meu lado o tempo todo preocupada comigo. [...] minha mãe sempre ficou comigo, quando não era ela, era a minha irmã. (M1)

[...] nossa... mudou tudo, outra vida agora, às vezes eu falo assim: 'queria ser que nem canguru, põe dentro da barriga pra ficar um pouco livre'. [...] é meio apertada (a rotina com os filhos), vamos dizer assim, ele trabalha e a maioria do tempo sou eu, sozinha. Minha família trabalha e não tem como (ajudar com os filhos). (M2)

Além da sobrecarga de trabalho da mãe, conforme mostram os relatos, M2 destaca outra mudança na dinâmica familiar, a de sofrer com o preconceito social, devido à condição neurológica do filho. Esta discriminação aconteceu até mesmo entre familiares próximos, como mãe, sogra e outros parentes e provocou ainda mais sofrimento:

[...] eu mais duas primas tivemos neném tudo no mesmo mês, como o delas não tem problema, minha avó pega no 
colo, abraça, brinca, conversa e ele (o filho) não. A única coisa que a minha avó sabia falar dele era 'tadinho, coitadinho, nosso tadinho', dele só falava isso e não pega, não faz nada, só com o das minhas primas. [...] quando eu vou lá na minha mãe, aí ele quer passar na mãe dele (esposo), ela pega ele um pouquinho e já devolve, eu também não faço questão não. (M2)

\subsection{Rede de atenção básica à saúde}

Neste estudo, as falas das mães evidenciaram fragilidades no processo de comunicação entre elas e a equipe de saúde da Atenção Básica, ou seja, da Estratégia de Saúde da Família.

[...] eu tive o atendimento no CRAS, só que quem me atendeu foi a Assistente Social e a Enfermeira, aí diz que tinha que passar por uma, como é que se fala (pausa) triagem para depois ver se eu ia precisar passar por uma Psicóloga, né. Depois, tinha que ver se eu ia passar ou não, eu falei: 'Não preciso disso aqui não! Vou para minha casa que eu ganho mais, vou trabalhar!'. Aí, eu larguei de mão, aí eu não fui mais. (M1)

[...] nunca...Médico, Enfermeiro, ninguém nunca me falou nada, até porque ninguém não conhecia, aí nunca tive essa ajuda, a equipe de saúde não perguntava, não ia atrás pra saber dele. (M2)

\section{Discussão}

O diagnóstico de microcefalia durante a gestação ou após o nascimento é um momento extremamente difícil para os pais e familiares, principalmente para a mãe. A forma como as informações são transmitidas e compreendidas é um aspecto importante a ser considerado e incorporado no planejamento da equipe de saúde, uma vez que, pode impactar negativamente na vida destas mulheres e no cuidado com a criança com microcefalia, por isso, é impossível desassociar este momento do cuidado humanizado, holístico e integral.

Nesta pesquisa, as mães relataram sentimentos tristes, angustiantes e desagradáveis após serem informadas sobre a microcefalia do filho. Estudos qualitativos (Costa et al., 2018, Oliveira et al., 2018, Sá et al., 2020, Bulhões et al., 2020, Sá et al., 2017, Menezes et al., 2019, Nascimento et al., 2019) que objetivavam desvelar a vivência de mães e/ou familiares de crianças com microcefalia, também, relataram o mesmo sofrimento emocional. Isso pode afetar a qualidade de vida familiar, visto que, esta sobrecarga emocional afeta o bem-estar de toda família. Um estudo, sobre qualidade de vida familiar, realizado com 50 famílias brasileiras que têm filhos com deficiência intelectual, identificou uma forte relação entre o domínio "bemestar emocional" e a qualidade de vida familiar. Além disso, este trabalho apontou a importância da construção de um plano terapêutico individualizado, como uma das medidas para acolher e oferecer suporte emocional às famílias (Oliveira et al., 2019).

O impacto da informação na vida das mães deve ser considerado como parte indissociável do cuidado integral à criança com microcefalia. Nesse sentido, aspectos positivos sobre como a criança com microcefalia pode ter melhores condições de vida e de saúde necessitam estar presentes na comunicação com as genitoras, como, por exemplo, a possibilidade de estimulação precoce das crianças, o acolhimento e o apoio permanente da equipe multiprofissional das Redes de Atenção à Saúde.

Dessa forma, receber informações sinceras e entendíveis sobre a microcefalia, bem como sobre o prognóstico, pode favorecer o aceite e fortalecer o vínculo entre a mãe e o filho. Isso contribui para que a mulher e sua família se preparem para o nascimento e, ainda, consigam lidar com consciência e tranquilidade com as fases de enfrentamento que surgirão após o nascimento da criança (Oliveira et al., 2018, Vale, Alves, Amorim, Carvalho, 2020). Por outro lado, a falta de conhecimento, 
favorece o desespero da família e dificulta a aceitação da criança e a oferta do cuidado necessário a ela (Costa et al., 2018, Oliveira et al., 2019).

De acordo com o estudo que realizou intervenções educativas em saúde com mães de crianças com microcefalia, a fragilização do vínculo entre a mãe e o filho pode estar relacionada à escassez de informações adequadas, o que leva à fragilização do cuidado à criança (Santos et al., 2019). Nesse tocante, é fundamental a articulação da equipe multiprofissional de saúde no cerne deste processo de orientação e de difusão de informações imprescindíveis aos cuidados e a promoção da saúde da criança com microcefalia (Oliveira et al., 2019, Santos et al., 2019). Ademais, a rede de cuidado deve estar consolidada para apoiar às mães e/ou cuidadores que muito precisam de ajuda, atenção e orientação (Pedrosa et al., 2020).

A investigação de Oliveira et al. (2019) que buscou compreender como os pais de crianças com microcefalia receberam o diagnóstico, revelou que, naquele período, quando os profissionais informavam a notícia, diziam apenas que algo parecia estar diferente. A fragilidade neste processo de comunicação pode estar relacionada ao medo, a ansiedade e a incerteza dos profissionais de saúde em relação às reações dos pais e familiares que receberão a notícia

Ainda, nesse sentido, outro estudo realizado, com 40 mães de crianças com microcefalia residentes na Paraíba (BR), uma das regiões brasileiras com maior número de casos registrados da doença durante a epidemia, evidenciou que oito mães vivenciaram uma experiência negativa quanto a forma como receberam a informação do diagnóstico do filho (Hamad \& Souza, 2020). O que também foi verificado na pesquisa realizada entre 2017 e 2018 no Maranhão (BR), em que houve omissão do diagnóstico para oito mães, seja no pré-natal ou após o nascimento (Oliveira et al., 2019). Frente aos resultados, torna-se necessário que haja um preparo dos profissionais, seja da saúde ou serviço social, para acolher, informar e acompanhar as famílias.

No período da epidemia de microcefalia, principalmente no início, os profissionais de saúde tinham poucos conhecimentos sobre os cuidados com crianças com microcefalia e, por isso, estudavam sobre o assunto para subsidiar a assistência e transmitir informações seguras e confiáveis aos pais no momento de comunicar o diagnóstico.

Mesmo diante de dúvidas e incertezas, o melhor caminho a ser trilhado pela equipe de saúde é o caminho da sinceridade e da transparência, por meio de uma comunicação empática, clara, adequada socio culturalmente, constante e permanente com as mães e familiares, que anseiam e merecem um acolhimento de qualidade e humanizado. Segundo Costa et al. (2018), a carência de informações assertivas é perturbadora às mães e pode prejudicar a tomada de condutas em relação aos cuidados com a criança com microcefalia e ocasionar a antecipação de prognóstico desfavorável, prejudicando e/ou minimizando o desenvolvimento das potencialidades da criança.

Para evitar informações inconsistentes ou confusas, é fundamental planejar a comunicação e como serão realizadas as orientações. Este é o ponto de partida das ações articuladas e pactuadas por multiprofissionais, de diferentes áreas do conhecimento, pois a sensibilidade do profissional envolvido neste processo e a forma como ele estabelece a comunicação pode ser um fator determinante para a aceitação e adaptação da família à criança com microcefalia. Dessa maneira os prognósticos e compreensão das capacidades e potencialidades do filho, essenciais para o empoderamento e equilíbrio familiar são ressignificados (Oliveira et al., 2018).

Diante da análise das entrevistas das participantes desta pesquisa, percebemos que, as mães passaram por um período de "luto" com a notícia de que teriam filhos com microcefalia, o que também foi relatado em um estudo nordestino (Hamad \& Souza, 2020). No presente trabalho, a M2 recebeu a notícia somente no puerpério imediato, desta forma, seu momento de dor veio seguido por um período de enfrentamento e superação. No entanto, quando ocorre o óbito, a sobrecarga emocional pode ser maior e levar à progenitora ao adoecimento mental, como ocorreu com a mãe M1, que relatou ter até pensamentos suicidas após a morte do filho. 
A perda de um filho no período perinatal gera nas mães uma dor devastadora com consequências psicossociais (Lopes, Martins, Carletto \& Borges, 2019). Fornecer uma rede de apoio de fácil acesso, humanizada e integral, no âmbito do Sistema Único de Saúde, é necessário para apoiar integralmente às mães que passam por luto e que lutam, constantemente, por políticas públicas que minimizem os danos causados pelo seu sofrimento, muitas vezes invisível aos olhos da sociedade (Melo \& Vaz, 2019).

Neste cenário de dor e sofrimento é necessário que profissionais qualificados (psicólogos, psiquiatras, enfermeiros, terapeutas e demais profissionais que atuam na área de saúde mental) ofereçam apoio psicológico às mães e familiares de crianças com microcefalia. Dessa forma, a família poderá lidar com as dificuldades encontradas e vislumbrar as possibilidades de explorar as potencialidades destas crianças (Crisóstomo, Grossi, \& Souza, 2019).

Em relação a dinâmica familiar, percebe-se que a rotina de M2 foi totalmente alterada, pois a mãe se tornou a principal cuidadora da criança, similarmente ao estudo de Pedrosa et al. (2020), realizado em João Pessoa (PB), em que cinco mães entrevistadas reportaram abandono do pai ou a falta de ajuda dele no cuidado com o filho com microcefalia. No presente estudo, também observamos a presença de preconceito no âmbito familiar, o que reforça a necessidade de uma rede de apoio sólida.

O diagnóstico da criança com microcefalia traz mudanças significativas na vida de toda família, principalmente da mãe, que, muitas vezes, precisa abandonar o trabalho, as atividades de lazer e se dedicar de forma exaustiva e exclusiva aos cuidados específicos com os filhos (Bulhões et al., 2020), necessitando contar com o apoio de toda a família para conseguir se adequar a essa nova dinâmica de vida.

Outros estudos também ressaltaram a alteração da dinâmica familiar e a sobrecarga materna, em decorrência dos cuidados diários dispensados à criança. Ainda, há outros relatos de preconceito, isolamento social e dificuldades socioeconômicas (Costa et al., 2018, Oliveira \& Sá, 2017, Sá et al., 2020, Nascimento et al., 2019, Oliveira et al., 2019, Santos et al., 2019, Lopes et al., 2019, Melo \& Vaz, 2019, Crisóstomo et al., 2019, Azevedo \& Spinazola, 2019).

Sobre o acolhimento nas Rede de Atenção à Saúde (RAS), as mães mencionaram alguns desencontros de informações, até mesmo a ausência de comunicação, o desinteresse e o desacolhimento de alguns profissionais de saúde. As progenitoras citaram, ainda, as dificuldades, desmotivantes, que elas enfrentam com a burocratização dos serviços essenciais à saúde da criança e da família. A ausência ou a insuficiência de comunicação entre as mães e os profissionais de saúde pode comprometer ainda mais a saúde da criança e dos familiares. Isso ocorre em virtude da ausência de encaminhamentos necessários para auxiliar as genitoras no desenvolvimento dos cuidados com a criança, ou devido à piora do contexto social e mental que esta mãe/família esteja inserida em razão desta síndrome. Sobre este aspecto, um estudo transversal, com 105 cuidadores de crianças com microcefalia, analisou a qualidade da RAS de crianças com microcefalia e demonstrou a insatisfação das mães com a qualidade dos serviços prestados pela RAS, em especial, na Atenção Primária (Santos, Silva, Lima, Reis, \& Oliveira, 2019).

A literatura aponta que a qualidade da comunicação das informações, no ato do diagnóstico de microcefalia, contribui para uma melhor compreensão por parte dos familiares sobre o tratamento e previne os anseios pelo estabelecimento da cura e evita o agenciamento de itinerários terapêuticos desgastantes (Vale et al., 2020). Conhecer as dificuldades enfrentadas pela família de criança com microcefalia, e aqui destacamos a importância ímpar da mãe, é primordial para concepção de políticas públicas e de projetos sociais muito além de ações assistenciais, mas que considerem a unidade e as subjetividades da família (Nascimento et al., 2019, Santos et al., 2019). Assim, pode-se vislumbrar a gênese de uma rede de apoio sólida, permanente, integral, humanizada, acolhedora, intersetorial e multiprofissional. Da mesma maneira, é imperativo um olhar atencioso e acolhedor por parte da equipe de saúde local, que deve oferecer estratégias de orientação e educação, em saúde, que incluam a capacitação parental, no contexto, de crianças com microcefalia pelo Zika Vírus. 


\section{Considerações finais}

As mães, que vivenciaram a experiência de ter um filho com microcefalia, reagiram ao diagnóstico com surpresa e desespero e ao luto com angústia e dor. Além disso, as progenitoras apresentaram pouco conhecimento sobre a doença e o prognóstico. Esta investigação evidenciou a mudança na dinâmica familiar frente à doença, e as dificuldades na interação da família com o setor básico de saúde. Portanto, é urgente a necessidade de acolhimento permanente e integral às mães, de forma que se estenda o cuidado com a saúde, não somente das crianças, mas, também, da unidade familiar.

Os estudos sobre este tema ainda são limitados na região Centro-oeste, sendo mais comum na região do Nordeste brasileiro. Por conta disso, nota-se a necessidade de abertura para novas pesquisas que possam explorar os impactos ocasionados na vida das mães e familiares das crianças com microcefalia, uma vez que, as políticas públicas, precisam continuar articulando e fortalecendo as diferentes redes intersetoriais de atenção às famílias.

As limitações deste estudo são atribuídas ao fato de ter sido utilizada uma amostra pequena de casos de microcefalia, mas que representava, na época, todas as ocorrências existentes na região pesquisada. Apesar disso, vale ressaltar que este é um estudo de cunho qualitativo, e, por isso, o tamanho da amostra não influenciou na qualidade e relevância dos resultados. Portanto, mais pesquisas, sobre o cuidado às crianças com microcefalia e seus familiares, devem ser feitas e estendidas para outros ambientes terapêuticos na atenção, primária e secundária à saúde.

\section{Agradecimentos}

Às mães e famílias brasileiras de crianças com microcefalia decorrentes da epidemia do vírus Zika, especialmente às mães que participaram deste estudo.

\section{Referências}

Azevedo, T. L., Cia, F., \& Spinazola, C. C. (2019). Correlação entre o relacionamento conjugal, rotina familiar, suporte social, necessidades e qualidade de vida de pais e mães de crianças com deficiência. Revista Brasileira de Educação Especial, 25(2), 205-218. doi: 10.1590/s1413-65382519000200002

Barros, S. M. M. D., Monteiro, P. A. L., Neves, M. B., \& Maciel, G. T. D. S. (2017). Fortalecendo a rede de apoio de mães no contexto da síndrome congênita do vírus zika: relatos de uma intervenção psicossocial e sistêmica. Nova Perspectiva Sistêmica, 26(58), 38-59. https://revistanps.com.br/nps/article/view/296

Brasil. Ministério da Saúde. Secretaria de Vigilância em Saúde. (2019). Síndrome congênita associada à infecção pelo vírus Zika: situação epidemiológica, ações desenvolvidas e desafios, 2015 a 2019. Boletim Epidemiologico, 50 (n.esp.), 1-31. http://www. saude.gov.br/boletins-epidemiologicos

Bulhões, C. D. S. G., Silva, J. B., Moraes, M. N. D., Reichert, A. P. D. S., Dias, M. D., \& Almeida, A. M. (2020). Repercussões psíquicas em mães de crianças com Síndrome Congênita do Zika Vírus. Escola Anna Nery, 24(2), e20190230. doi: 10.1590/2177-9465-EAN-2019-0230

Buscaglia, L. F. (2010). Os deficientes e seus pais: um desafio ao aconselhamento, 6 a Edição. Rio de Janeiro: Record.

Costa, E. D. S., Bonfim, E. G., Magalhães, R. D. L. B., \& Viana, L. M. M. (2018). Vivências de mães de filhos com microcefalia. Revista Rene, 19(e3453), 18. doi: $10.15253 / 2175-6783.2018193453$

Crisostomo, K. N., Grossi, F. R. S., \& Souza, R. S. (2019). As representações sociais da maternidade para mães de filhos/as com deficiência. Revista Psicologia e Saúde, 11(3), 79-96. doi: 10.20435/pssa.v0i0.608

Fantinato, F. F. S. T., Araújo, E. L. L., Ribeiro, I. G., Andrade, M. R., Dantas, A. L. M., Rios, J. M. T., Silva, O. M. V., Silva, M. S., Nóbrega, R. V., Batista, D. A., Leite, P. L., Saad, E., Percio, J., Resende, E. A., Souza, P. B., \& Wada, M. Y. (2016). Descrição dos primeiros casos de febre pelo vírus Zika investigados em municípios da região Nordeste do Brasil, 2015. Epidemiologia e Serviços de Saúde, 25(4), 683-690. doi: 10.5123/S1679-49742016000400002

Felix, V. P. S. R., \& Farias, A. M. (2017). Microcefalia e dinâmica familiar: a percepção do pai frente à deficiência do filho. Cadernos de Saúde Pública, 34(12), e00220316. doi: 10.1590/0102-311X00220316

Hamad, G. B. N. Z., \& Souza, K. V. (2020). Síndrome congênita do Zika vírus: conhecimento e forma da comunicação do diagnóstico. Texto \& Contexto Enfermagem, 29, e20180517. doi: 10.1590/1980-265X-TCE-2018-0517

Lesser, J., \& Kitron, U. (2016). A geografia social do zika no Brasil. Estudos Avançados, 30(88), 167-175. doi: 10.1590/S0103-40142016.30880012

Lopes, B. G., Martins, A. R., Carletto, M. R., \& Borges, P. K. O. (2019). A dor de perder um filho no período perinatal: uma revisão integrativa da literatura sobre o luto materno. Revista Stricto Sensu, 4(2), 29-40. doi: 10.24222/2525-3395.2019v4n2p029

Melo, C. T. V., \& Vaz, P. R. G. (2019). Perda gestacional e neonatal, um sofrimento como outro qualquer. Revista Matrizes, 13(2), 91-112. doi: 10.11606/issn.1982-8160.v13i2p91-112 
Melo, D. G. S., Silva, H. F., Moura, I. T. T., \& Barbosa, S. S. (2017). Aceitação paterna diante o diagnóstico de microcefalia. Psicologia pt - O Portal dos Psicólogos, 1-14. https://www.psicologia.pt/artigos/textos/A1109.pdf

Menezes, M. G. V., Mendes Neto, J. M., Leal, C. N. L., Vasconcelos, A. P. L., Aragão, H. T., Silva, N. V., \& Luz, L. K. T. (2019). Dificuldades E Estratégias Da Família No Cuidado Da Criança Portadora De Microcefalia. Revista Enfermagem Atual in Derme, 88(26), 1-7. http://revistaenfermagematual.com.br/index.php/revista/article/view/158

Minayo, M. C. S. (2012). Análise qualitativa: teoria, passos e fidedignidade. Ciência \& Saúde Coletiva, 17(3), 621-626. Recuperado de: https://www.scielo.br/pdf/csc/v17n3/v17n3a07.pdf

Nascimento I. P., Gomes, R. M., Vieira, S. N. S., Guedes, T. P., Santana, G. J., \& Silva, F. N. (2019). Vírus zika e microcefalia: a mãe frente o diagnóstico do filho. Revista Interscientia, 7(1), 54-65. https://periodicos.unipe.edu.br/index.php/interscientia/article/view/918

Oliveira, É. B. C., Pereira, R. C. M., Apis, A., Germano, C. M. R., Pilotto, R. F., \& Melo, D. G. (2019). Qualidade de vida de famílias de filhos com deficiência intelectual moderada. Journal Brasileiro de Psiquiatria, 68(2), 101-109. doi:10.1590/0047-2085000000233

Oliveira, M. C., \& Sá, S. M. (2017). A experiência parental após o diagnóstico da microcefalia por zika vírus: um estudo de caso. Revista Pesquisa em Fisioterapia, 7(4), 511-517. doi: 10.17267/2238-2704rpf.v7i4.1602.

Oliveira, M. C., Moreira, R. D. C. R., Lima, M. M., \& Melo, R. O. (2018). Vivências de mães que tiveram filhos com microcefalia. Revista Baiana de Enfermagem, 32, e26350. doi:10.18471/rbe.v32.26350

Oliveira, P. S. D., Lamy, Z. C., Guimarães, C. N. M., Rodrigues, C. B., Silva, A. A. M. D., Simões, V. M. F., \& Sousa, P. S. (2019). Experiências de pais de crianças nascidas com microcefalia, no contexto da epidemia de Zika, a partir da comunicação do diagnóstico. Cadernos de Saúde Pública, 35(12), e00226618. doi: 10.1590/0102-311X00226618

Pedrosa, R. K. B., Guedes, A. T. A., Soares, A. R., Vaz, E. M. C., Collet, N., \& Reichert, A. P. S. (2020). Itinerário da criança com microcefalia na rede de atenção à saúde. Escola Anna Nery, 24(3), e20190263. doi: 10.1590/2177-9465-EAN-2019-0263.

Pimenta, M., Pereira, S., Clode, N., \& Graça LM. (2016). Vírus Zika e gravidez. Acta obstétrica ginecológica Portuguesa, 10(2), 92-94. Recuperado de: http://www.scielo.mec.pt/pdf/aogp/v10n2/v10n2a02.pdf

Sá, F. E., Andrade, M. M. G., Nogueira, E. M. C., Lopes, J. S. M., Silva, A. P. É. P., \& Assis, A. M. V. (2017). Produção de sentidos parentais no cuidado de crianças com microcefalia por vírus Zika. Revista Brasileira em Promoção da Saúde, 30(4), 1-10. doi: 10.5020/18061230.2017.6629

Sá, S. A. A. G. D., Galindo, C. C., Dantas, R. S., \& Moura, J. C. D. (2020). Dinâmica familiar de criança com a síndrome congênita do Zika vírus no Município de Petrolina, Pernambuco, Brasil. Cadernos de Saúde Pública, 36(2), e00246518. doi: 10.1590/0102-311X00246518

Sá, S. M. P., \& Rabinovich, E. P. (2006). Compreendendo a família da criança com deficiência física. Revista Brasileira de Crescimento e Desenvolvimento Humano, 16(1), 68-84. https://www.revistas.usp.br/jhgd/article/view/19782/21850

Santos, D. B. C., Prado, L. O. D. M., Silva, R. S., Silva, E. F., Cardoso, L. C. C., \& Oliveira, C. C. C. (2019). Sensibilização das mães de crianças com microcefalia na promoção da saúde de seus filhos. Revista da Escola de Enfermagem da USP, 53, e03491. doi: 1590/S1980-220X2018022903491

Santos, D. B. C., Silva, E. F., Lima, S. O., Reis, F. P., \& Oliveira, C. C. C. (2019). Rede de atenção à saúde: percepção materna quanto à qualidade de atendimento de crianças com microcefalia. Esc Anna Nery, 23(4), e20180335. doi: 10.1590/2177-9465-EAN-2018-0335

Santos, D. S. S., Mercês, M. O., Souza, R. L., \& Santana, A. L. (2018). Cuidados a criança com síndrome congênita do zika: Revisão sistemática. Revista Brasileira de Saúde Funcional, 6(1), 81-92. http://www.seer-adventista.com.br/ojs/index.php/RBSF/article/view/1015/788

Vale, P. R. L. F., Alves, D. V., Amorim, R. C., \& Carvalho, E. S. S. (2020). A rosácea do cuidado às crianças com síndrome congênita por zika: atitudes cuidativas dos familiares. Escola Anna Nery, 24(3), e20190268. doi: 10.1590/2177-9465-EAN-2019-0268 